\title{
SOFT OR APPROACHES
}

René Victor Valqui Vidal ${ }^{1}$

\begin{abstract}
This paper is an inquiry into the nature and characteristics of the so-called soft approaches in Operational Research (OR). After a first outline of soft approaches, six wellknown and widely applied soft approaches are selected for further study and characterisation applying a multi-dimensional framework. In addition, some reflexions about the limitations of such a framework are discussed.
\end{abstract}

Keywords: Soft OR, SWOT, Future Workshops, SODA, SCA, Scenarios, SSM.

\section{INTRODUCTION}

During the past two decades, we have seen an increasing development and use of the so-called soft approaches within OR and other related disciplines. Moreover, recent OR textbooks as Daellenback (1994) and Pidd (1996) include in their contents both hard and soft approaches. Although, it is clear what is meant by the concept "hard approaches" the situation is not the same with the concept "soft approaches". There are many soft approaches being somehow similar, somehow different. Therefore, we believe that there is a need for a more systematic characterisation of soft approaches.

The main purpose of this paper is to carry out an inquiry process with the purpose of characterising the so-called soft approaches. We believe that such an inquiry will be useful to get a multidimensional insight on the properties of some selected soft approaches.

In section 2, we discuss the question: "What are soft approaches?" A first characterisation is outlined. In section 3, we select six soft approaches for further study. The selected soft approaches are described in section 4 in terms of function and methodology. In section 5 , we present a general framework for characterisation of soft approaches. Section 6 includes an overall characterisation made of the selected approaches. Section 7 presents some reflexions about the limitations of the presented framework while the last section, presents the conclusions.

\section{WHAT ARE SOFT APPROACHES?}

A point of departure for our inquiry could be to give an answer to the following question: What are the differences between "hard" and "soft" approaches?

The differences between hard and soft approaches can be summarised as shown in Table 1.

The main limitation of previous analyses (Checkland, 1981; Rosenhead, 1989) is the focus only on the methodological and modelling aspects of the problem solving process, disregarding the other dimensions outlined in Table 1. Now a day, there are soft approaches that not are based on applied modelling or/and systems thinking but on negotiation, dialogue, creativity and/or learning as tools for group problem solving.

Previous characterisations of soft approaches are uni-dimensional focusing either on system thinking or/and qualitative modelling. Therefore, we are

\footnotetext{
1 Informatics and Mathematical Modelling, Technical University of Denmark, DK-2800 Lyngby, vvv@imm.dtu.dk
} 
searching for a multi-dimensional characterisation of soft approaches.

Table 1 Hard vs. Soft approaches

\begin{tabular}{|lll|}
\hline & Hard & Soft \\
\hline Problem situation & Well-defined & Mess (problematic) \\
\hline Purpose & Problem solving & Problem structuring \\
\hline Organisation & Given & To be negotiated \\
\hline Methodology & $\begin{array}{l}\text { Logical/mathematical model, } \\
\text { the OR worker is an expert }\end{array}$ & $\begin{array}{l}\text { Conceptual models, the } \\
\text { OR worker is a facilitator }\end{array}$ \\
\hline Result & Product/recommendation & $\begin{array}{l}\text { Learning process, action } \\
\text { plan }\end{array}$ \\
\hline
\end{tabular}

\section{SELECTING SOFT APPROACHES}

Continuing with our inquiry and for the sake of concreteness we want to select some approaches for further study. This is not an easy task because there are many approaches. To keep this paper within a reasonable length we decided to select six approaches that somehow were representative in textbooks and related papers, and with their applicability well documented by solving real-life messes.

We consulted the following books that present several soft approaches: Rosenhead (1989), Flood and Jackson (1991), Keys (1991), and more applied texts as: Dyson and O'Brien (1998), Sørensen and Vidal (1999), and Richie et al. (1994).

The different approaches, at first sight could be classified as focusing either on supporting the group's work in the problem solving processing or in supporting the modelling process. From the first group we selected: the SWOT analysis and the Future Workshop. From the second group, we selected: Strategic Options Development and Analysis (SODA), Strategic Choice Approach (SCA), and Soft Systems Methodology (SSM). In addition, we have also included the Scenario approach because depending in how it is designed; it could be situated in the first or the second group. Obviously, we could have included other approaches but the approaches selected are those that we have more practical experiences with through our research, teaching and consulting work. Moreover, we have disregarded very popular approaches that provide very advanced interactive and ENGEVISTA, v. 7, n. 1, p. 4-20, abril 2005 user-friendly software such as System Dynamics, Analytical Hierarchy Process, Linear Programming, etc., that make their use very easy because the final purpose is the construction of a mathematical model. In other words, we have discarded approaches that provide soft use of hard methods.

Another important aspect in the characterisation of the above mentioned approaches is the role that the OR-worker is going to play in the problem solving process. This role might change very widely from expert (in for example a specific technology), to specialist in a particular method (such as SODA), to facilitator of a social process (as for example in the Future Workshop) and to analyst (as for example in relation to conflicts in group work). As we will see later, some approaches demand one or several roles of the OR-worker.

\section{SIX SOFT APPROACHES}

The soft approaches selected in the last section have been applied to many different problematic situations to support problem solving. Classical applications can be found within the areas of: strategic development, planning, design, project selection/evaluation, etc.

In this section we will give a short presentation of each approach in its more general form as originally presented by the originators of each of these approaches. Obviously, in real-life problem solving each approach will be modified or tailored to the specific situation and to how the problem solving process will be carried out. These were easy to implement for five of the six approaches, the Scenario 
approach being problematic. This is due to the fact that the Scenario approach represents a whole spectrum of approaches from quantitative modelling to soft sociological approaches. The presentation on the scenario approach is, therefore, our own based on several real-life soft applications.

\subsection{THE SWOT ANALYSIS (WEIRICH, 1982)}

The SWOT analysis is one of the simplest approaches that can be carried out and be used in supporting strategy development and planning. It has the overall purpose to structure both qualitatively and quantitatively the situation a specific organisation is in, and to investigate which elements in the organisation and its surroundings may influence its future existence. It was originally developed and used in business organisations and is based on a business view of planning.

\section{Going through a SWOT analysis}

The analysis concentrates on the grounds for the existence of the organisation, on its current situation, development of strategies, and selection of one or more strategies to implement.

The SWOT analysis can formally be described through the following steps:
1. Identify the organisation's internal strengths and weaknesses and its external options and threats. The different points are usually found by using the experience and knowledge of the individuals in the organisation through a discussion and brainstorming process (workshops).

2. If a large number of points have been identified, it may be necessary and worthwhile to make a qualitative evaluation of each point to prioritise the different points. For each of the points identified under the strengths and options, evaluations are carried out in terms of stability and consequence. Stability and consequence can be either significant or small. This means that for example strengths with significant consequence and stability have a higher priority than other points. Correspondingly, the weaknesses and threats are evaluated in terms of consequence and change (again on a significant - small scale).

3. The different points are then placed into the so-called SWOT matrix. If the points have been prioritised, they should be placed in the boxes after importance. The matrix is shown in Figure 1.

\begin{tabular}{|l|l|l|}
\hline & $\begin{array}{l}\text { Internal strengths } \\
\bullet\end{array}$ & $\begin{array}{l}\text { Internal weaknesses } \\
\bullet\end{array}$ \\
\hline$\bullet$ & Maxi-maxi strategies & Mini-maxi strategies \\
\hline $\begin{array}{l}\text { External threats } \\
\bullet\end{array}$ & Maxi-mini strategies & Mini-mini strategies \\
\hline
\end{tabular}

Figure 1 The SWOT matrix

weaknesses and maximise options

4 Now strategy areas can be identified based on matching of the SWOT points. In principle there are four types of strategies to formulate (see again figure 1): the strategies that maximise options and strengths (maxi-maxi), the strategies that minimise the (mini-maxi), strategies that maximise strengths and minimise threats (maximini), and strategies that minimise both threats and weaknesses (minimini). In spite of the different types of strategies, they are not always independent. Organisations often find 
themselves having a mixture of strengths, weaknesses, options and threats and therefore it is important to analyse and prioritise all the abovementioned types of strategies. The strategies themselves are formulated using experience, common sense, intuition, and fantasy of the participants and/or the OR-worker.

5 Finally, the strategy or strategies that seems most relevant are analysed further and an implementation plan is developed.

SWOT is a very simple matrix model for structuring ideas and concepts to be able to identify strategy areas. SWOT does not specify how the problem solving process is to be carried out.

When applying the SWOT analysis it is up to the OR-worker (and clients of the organisation) to define the extent to which the approach shall be used as a model or a part of a problem solving process. Therefore, the OR-worker's role can be anything from an expert to a facilitator. SWOT has been used by single individuals, to support a group process, or in workshops in both public and business organisations.

\subsection{THE FUTURE WORKSHOP (JUNK AND MÜLLERT, 1987)}

The future workshop was developed among citizen groups and grassroots. The fundamentals behind the workshop were to provide these people with common background for formulating suggestions (strategies) for changing a problematic situation into a situation they agreed on would be improved. The suggestions were to be presented for others to decide on. The workshop builds on democratic principles, engagement, participation, and an interest for common problems.

The future workshop has been applied in a large number of cases within municipalities, youth centres, unions, etc. Also it is seen used in business organisations and firms. Through these applications and evaluations, the workshop has been modified and changed according to the situation in which it was used.

\section{The phases of the future workshop}

By establishing a future workshop it is the intention to focus on a specific problematic situation, generate visions about the future and discuss how these visions can be realised. Participants of the workshop share the same problem, and have a wish to change the situation. As the name implies, a workshop is carried out. The future workshop is made up by the following five phases:

1. The preparation phase has the overall purpose of creating the necessary frames for the workshop so it will not be disturbed by practicalities when started. Examples on practicalities are deciding on the theme, finding locations for carrying out the workshop, finding participants, getting pens, paper, 3-M Notes blocks, etc., buying food and drinks for the participants.

2. The critical phase where the problem is described through criticism of each of the members of the workshop. Presenting individual critical views on the problem situation shall both broaden the theme with details, and create a common knowledge base for all participants on the problem situation. Each member of the workshop presents his/her critical items, complaints, anger or worries related to the problem. It is not allowed for others to respond to, criticise or comment on these points. After this first presentation, some points are selected for further work. Such selection may be based on prioritising the items for example by allocating points to each item (or simple voting). Hereby, the group formulates one or more themes for the remaining workshop.

3. The fantasy phase where positive solutions are formulated based on visions, wishes and hopes. In this phase the critical items and themes are changed into positive statements, visions and even utopias for the future. As the name implies, 
creativity and fantasy is used to formulate visions. Suggestions on solutions are given on a spontaneous basis and brainstorming. Prioritising the visions for future work also finishes this phase.

4. The realistic phase where the critical problem areas and the positive solutions are compared with the options and limitations of reality to form realistic strategies. More realistic suggestions must now be formed. The visions must be changed into real project proposals through looking at the limitations of reality and making adaptations accordingly. This takes place through discussions, more prioritisation, getting information from literature, media, etc., to get ideas of how they can be realised. Also economic aspects must be looked into as well as the expected critique or support that may follow the presentation of the suggestions. Suggestions are presented for decision-makers.

5. The follow-up phase where the process itself is evaluated as well as the new situation. Also the results of the workshop are to be presented to a larger crowd.

The Future Workshop primarily focuses on the problem solving process.

Carrying out the workshop requires a facilitator. He/she shall lead the workshop through the phases of the workshop and make sure that timeframes are held, all phases are carried out, and all individuals are heard. At the same time he may assist as secretary for the workshop and have a limited leading role.

\subsection{THE SCENARIO APPROACH (VIDAL, 1996)}

Originally, scenario analysis, scenario method, scenario writing are concepts used about certain techniques and steps leading to construction of quantitative scenariospictures of the future. Traditional OR methods have been used as techniques and tool. However, applications and new ways of thinking have given a more flexible structure to the act of creating scenarios. In some situations, the meaning of the concepts is more a flexible frame for the users to decide which tools, methods, and models to support and carry out different parts. Therefore, we refer to the scenario approach to represent the flexibility more than the precise stepwise directions.

The concepts of scenario and scenario approach have come to mean different things to different people. Here we operate with the broad definition of a scenario meaning a description or presentation of a future as well as the corresponding actions (the ways) that lead to this future.

For years, scenarios have been used in planning activities in public and private organisations. Scenarios are here used as a part of the first steps in the process leading to strategy and plans. Usage of scenarios, therefore, has several purposes:

- To find and identify priority problems (key variables) for the organisation by looking at relations between variables in the areas of focus

- To determine the central actors and their strategies as well as resources and means to make a successful project

- To describe (in scenarios) the development of a certain system in focus by taking into account the most likely developmental trends of the key variables and to look on the different actors' influence.

\section{The Frames of the Approach}

The scenario approach involves problem structuring, a methodological aspect in the process, and engagement between the different actors. There exists a long number of ways of structuring the problem as well as methodological approaches and techniques-it is up to the ORworker/participants of the scenario methodology to select which ones to use and through this choose the level of interplay between the actors. Here we shall comment on two aspects of the scenario methodology: the problem structuring, and the methodological aspects. 
The problem structuring

In the problem structuring the following areas are considered:

- Approaches for describing the system in focus using either the inductive or deductive principle. Using the inductive principle implies looking at the system and its parts-it's fundamental factors-and their functions and relations are analysed. From this picture, alternative scenarios are constructed. The deductive principle also analyses the whole system but decomposition is not performed. Using this principle requires a large number of factors to describe alternative futures. The deductive principle is often carried out using qualitative data; intuition and soft approaches while the inductive principle more commonly uses quantitative data, analytical thinking and traditional OR methods.

- Approaches that can take care of the dynamics of the system in focus by applying the anticipatory or explanatory principle. Focusing on the structuring of the dynamics in the system, the anticipatory approach can be used. Here one starts with a certain future picture of the system as it has more or less been decided would be the most desirable picture (could be specified from for example political goals and directions). The problem is then to finding the possible ways leading from the specific future picture to the known present situation. In the explanatory approach, the present situation is investigated under different sets of trends and assumptions giving a range of different future pictures of the system in focus.

The methodological aspects

Two schools of thought are behind the scenario methodology: the American school building on quantitatively oriented methods (Kahn and Wiener, 1967), and the French school based on more informal ways of handling the situation in a mixture of methods and methodologies, intuition, discussions and workshops (Godet, 1987). In either case the scenario methodology can technically be based on a combination of steps. The steps are directed to investigating the system (organisation or problem area), the surroundings of the system, historical trends, present situation, identifying key variables, constructing scenarios and alternative strategies. Each step can be carried out or supported technically and methodologically by various approaches.

It shall be mentioned that scenarios are constructed based on different themes, as various types and with different meanings, with varying time horizon, and in different numbers.

It is the methodological aspects used that define the role of the OR-worker in the scenario methodology. He may therefore be both expert and facilitator in the process.

\subsection{Strategic Option Development and Analysis (Eden, 1988)}

Strategic Option Development and Analysis (SODA) has its roots in the fields of soft OR and cognitive psychology. SODA is a way of working with a group of people and a technique for constructing cognitive maps of how people perceive and think about a problematic situation. It is used when groups of people both individually and commonly may have difficulties in defining and structuring their perception of a problematic situation.

SODA is made up by a number of concepts and theoretical perceptions about how we think and act. The concepts and theories are based on the following views:

- That each individual perceives the world subjectively.

- That processes and negotiations make up the organisation more than structures. Little weight is put into official power relations.

- That the planner's function is defined as being supportive in the above mentioned negotiation processes so decisions can be reached through consensus in 
contrast through demonstrations of power.

- That the primary tool or technique used is cognitive maps. The cognitive map is a way of trying to grasp different ways of thinking and to involve all partners to redefine the problem perceptions and form ground for commitment and consensus decisions.

\section{The SODA Dynamics}

SODA is technically based on the creation and analysis of cognitive maps. A cognitive map is a way of visually presenting an individual's perceptions about a problematic situation and the linkages between the different actions and consequences. As such a sort of network is formed. Cognitive maps are based on Kelly's theory on personal construct. Cognitive maps are constructed through an interview where the planner creates the map along the way.

Shortly, the process of SODA can be outlined as follows:

- Individual problem construction where each individual of the group is interviewed about the problem situation and cognitive maps are created.

- Individual problem acknowledgement where maps are analysed and each map is presented for the individuals again for discussion and acceptance. Some times another interview can be carried out.

- Group redefining the situation, which involves that, a merged map is created, based on the individual maps. The merged map includes perceptions of all individuals and in this way it represents all the members of the group. Through the merged map, they can commonly redefine the problem situation.

- Group consensus on a number of strategies where a negotiation process has been carried out based on the redefined problem situation, and solutions are found. It is assumed that consensus and engagement lies behind the sequence of strategies being the visible results of SODA.

The OR-worker has a facilitative role in supporting the process. However, he also has an analysing role and hereby easily becomes in a position where he may lead the process.

It shall be mentioned that SODA is a dynamic, cyclic process that may jump between the outlined steps.

\subsection{STRATEGIC CHOICE APPROACH (FRIEND AND HICKLING, 1997)}

The Strategic Choice Approach, SCA, has a background in OR. It has been used especially in public organisations for strategy development and planning. SCA can be characterised as a planning approach that centres on dealing with the uncertainty of problematic situations and decisions. SCA is carried out to support a group of decision-makers in deciding on which strategies to follow.

Through its focus on decision areas, uncertainty and criteria, SCA has common features with the field of Multicriteria Decision Analysis (MCDA). However, SCA uses a structuring of the problem situation and discusses solutions through workshops while the MCDA field builds on quantitative representations and calculations for solutions.

\section{The Modes of SCA}

In SCA the planning process is divided into four modes: shaping, designing, comparing and choosing. The modes can be operated in a cyclic process where the users of SCA can jump between the different modes. In the following the modes of SCA are referred to in a linear way. Each mode consists of a number of steps that are carried out using special techniques. The modes are:

- Shaping. In the shaping mode, the decision areas and problem focus is decided upon. This means that the group of participants outlines the decision areas of their planning problem, looks at their linkages and decides which ones are more urgent to 
focus on.

-Designing. The most urgent decision areas are now analysed in terms of different decision options and their interconnectedness. A special technique is used to limit the decision options by looking at their incompatibility. Decision schemes are constructed to outline the different feasible combinations of decision options to work with for the remains of the workshop.

- Comparing. Different criteria or comparison areas are now discussed to find out about the requirements for the strategies to construct. Assessments of the various combinations of decision options and comparisons are made.

-Choosing. For the combinations of decision options that look most promising, considerations to uncertainties of different types are made. Additionally, it is decided how these uncertainties can be dealt with for example by taking stepwise decisions. Action schemes and commitment packages are constructed to outline the different decisions that are made now and in the future.

It is the intention that the OR-worker shall work as a facilitator of the process. However, he may have to be an expert in using the concepts and techniques of SCA to be able to support the process.

\subsection{SOFT SYSTEMS METHODOLOGY (CHECKLAND, 1981)}

Through the 1970's the Soft Systems Methodology, SSM, was developed. Since then, SSM has been modified and changed several times and it is in that way a methodology that tries to fit into the applications where it is used.

SSM is used to analyse and improve problematic situations characterised as messy. It acknowledges that individuals have subjective views on the problematic situation (their world views) and through a learning system, they are learning about the problem, acknowledging others' views, comparing, and finding ways (strategies) to improve the situation. SSM is used in a group of individuals.

\section{The Process of SSM}

SSM works its way through mixing the real worlds' perceptions with a Systems Thinking way of working with the perceptions. It is, in short, based on the following steps:

- Structuring and expressing the problem situation. In this first step the unstructured problem situation is described for each participant in terms of his worldview (the German concept of Weltanschauungen is used). Rich pictures (cartoon like pictures) are constructed to visualise the way one person perceives the problematic situation.

- Construction of conceptual models. From the rich pictures, a conceptual model is constructed. The model intends to stimulate to debate and visually present what needs to be decided on. The verbal models are constructed by looking at operational activities needed to change the problematic situation, activities to monitor and control that the change takes place and the criteria for monitoring.

- Comparing and changing worldviews. Now the models are compared and used to discuss differences in perception and ways of 'solving' the problems. Hereby, accommodations to subjective worldviews take place. Another cycle in the process can then be taken or decisions on which strategies to develop to confront the problems may be decided on.

The OR-worker is here again both the facilitator in terms of supporting the process but must also be the expert in the concepts and way of thinking that lies in the approach.

\section{CHARACTERISATIONS}

Even though the six approaches are based on the same fundamental purpose of supporting problem solving, they are quite 
different in terms of focus point, the role of the OR-worker, involvement of the individuals in the organisation, organisational view, technologies used, etc. In order to evaluate and compare the approaches in terms of their support in specific problematic situations and to get a quick introduction to their features, and differences, a characterisation framework can be used.

\subsection{THE CHARACTERISATION FRAMEWORK}

The characterisation framework is presented using a diamond as symbol for a specific approach to be evaluated. The diamond symbolises four central dimensions of the features of the specific approach. Figure 2 illustrates the framework.
The approach is characterised in terms of the four measures: process, products, organisation and technology. The diamond symbolises that the dimensions are interrelated and cannot be evaluated alone. Each of the dimensions shall be presented in the following.

\section{The Process}

This dimension considers whether the approach includes explicit or implicit guidelines for how the OR-worker and/or the group of participants shall address the group's way towards obtaining visible or invisible products. 'The process' focuses on how time is used most efficiently while it at the same time is seen to that the group of individuals goes through the necessary considerations in terms of reaching the wanted results of applying the approach.

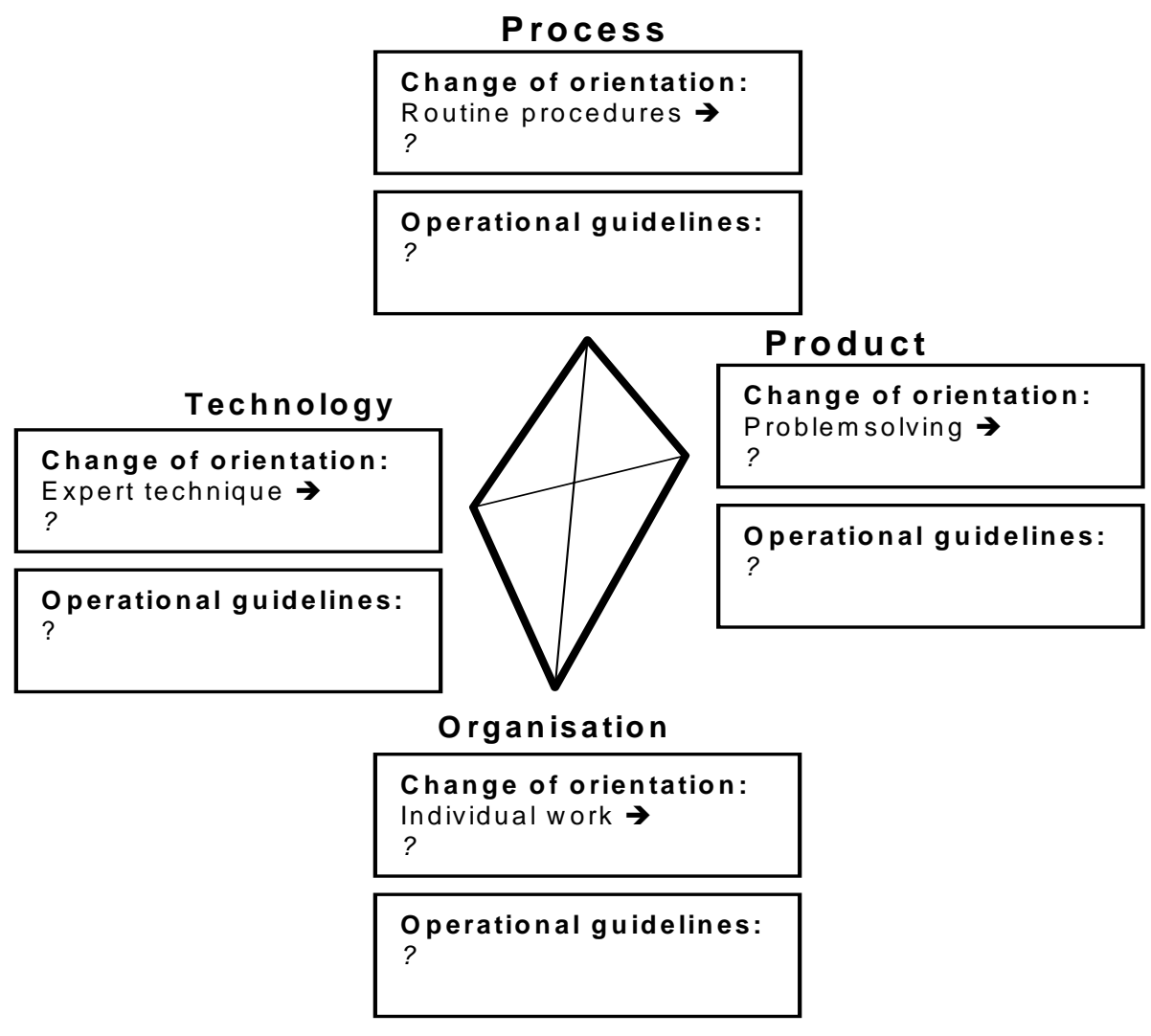

Figure 2 Overview of the dimensions of an approach (based on Friend and Hickling, 1997). The figure shows how an approach is oriented in terms of guidelines in relation to process, product, organisation and technology. For each dimension it is evaluated how the approach in focus is different from the traditional OR methods

\section{The Products}

Products of can be obtained at different levels, in terms of substance and in terms of processes. Products of substance are products, which are rather concrete and clear for the involved individuals. They can be either visible or invisible. Visible products of substance are associated with actions, policies and strategies developed 
as part of the process. Those are the products traditional OR methods focus on. Invisible products of substance are associated with changes in perception; the individuals themselves have followed during and after the application. An example of invisible products of substance is an extension of individual views on the problem situation.

Products of the process are linked to the approach and the way it guides the process. Visible products of the process are more or less documented commitment to being willing to change the situation, exploring it and using various procedures. Invisible products of the process are the common appreciation to being willing to working with the limitations of the social, political, cultural and resourceful systems of the organisation. It is here looked upon if the approach in focus supports a process that leads to obtaining this kind of results and relating to the problem situation.

An illustrative overview of the different products can be found in Figure 3.

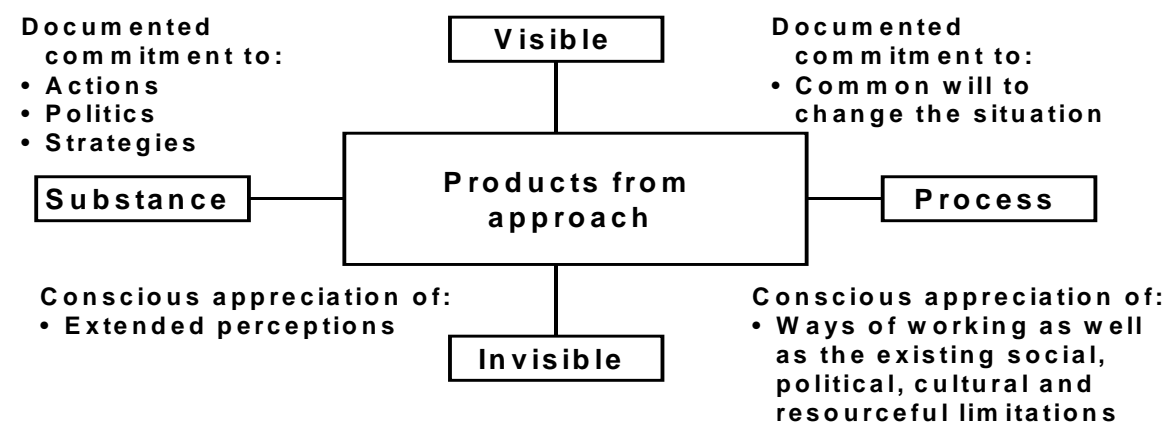

Figure 3 Classification of products

\section{The Organisation}

The third dimension describes how the work is organised. This includes looking at the individuals and their way of being involved in the process (interactive modus). Hereby reflections can be made to the organisational view lying behind and inherently in the approaches. This has an important meaning in terms of the products the process will leave.

\section{The Technology}

The last dimension, the technology, refers to the 'tools' or techniques used in the process, i.e., the special structuring, modelling, and perhaps programming tools such as pencils and software programmes. An evaluation of these tools and techniques is important because of their influence on the process and the individuals' possibility to understand the process and its results. The more complicated the technologies the more likely it is that the participants will have difficulties in understanding and accepting the products produced.

\section{CHARACTERISATION OF THE SIX APPROACHES}

The framework has been used to evaluate and compare the six approaches presented in the paper. Tables 2 and 3 include a short description of each of the approaches using the concepts from the framework, information on background, and the role of the OR-worker involved.

Comparing the approaches, it is clear that the SWOT analysis and the scenario methodology are close to traditional OR. Both approaches are in terms of background and the linear way of working not necessarily supported by a dynamic group process. The characterisation of being soft approaches is dependent on the way they are applied both by the ORworker and the involved participants. Viewing objectively on the descriptions of their way of working, they have no focus on supporting an interactive learning process, they focus on visible results of substance, can be applied individually or in groups, uses various technologies, and require an OR-worker who must be an expert of the approach but also can be an analyst. It is the way they are applied, and 
the OR-worker and participants (and the clients/decision-makers of the organisation) who decide whether there are changes from the traditional OR methods view to the more soft approach characterisations.

Table 2 Overview of the evaluation of the three approaches the SWOT-analysis, future workshop and the scenario methodology

\begin{tabular}{|c|c|c|c|}
\hline $\begin{array}{l}\text { Characteristics } \\
\text { of }\end{array}$ & SWOT analysis & Future workshop & $\begin{array}{l}\text { Scenario } \\
\text { methodology }\end{array}$ \\
\hline Background & Business & $\begin{array}{l}\text { Social psychology/ } \\
\text { sociology }\end{array}$ & $\begin{array}{l}\text { OR and systems } \\
\text { analysis }\end{array}$ \\
\hline Focus & $\begin{array}{l}\text { Identification of critical } \\
\text { success factors. Match } \\
\text { between the org. And } \\
\text { its surroundings }\end{array}$ & $\begin{array}{l}\text { Based on individual } \\
\text { dissatisfaction, a } \\
\text { common strategy is } \\
\text { searched }\end{array}$ & $\begin{array}{l}\text { Formulation of strategy } \\
\text { for the organisation }\end{array}$ \\
\hline Process & $\begin{array}{l}\text { No special conside- } \\
\text { rations and guidelines } \\
\text { to the process, usually } \\
\text { guided in a linear } \\
\text { process by the analyst }\end{array}$ & $\begin{array}{l}\text { Three work phases } \\
\text { with individual and } \\
\text { interactive par- } \\
\text { ticipation of all } \\
\text { involved }\end{array}$ & $\begin{array}{l}\text { No special conside- } \\
\text { rations and guidelines } \\
\text { in the process, usually } \\
\text { guided in a linear } \\
\text { process by the analyst }\end{array}$ \\
\hline Products & $\begin{array}{l}\text { Focus on visible } \\
\text { products of substance } \\
\text { and establishment of } \\
\text { action oriented stra- } \\
\text { tegies }\end{array}$ & $\begin{array}{l}\text { Products in all cate- } \\
\text { gories. Focus on in- } \\
\text { visible results }\end{array}$ & $\begin{array}{l}\text { Focus on visible } \\
\text { products of substance } \\
\text { and establishment of } \\
\text { action orientated } \\
\text { strategies }\end{array}$ \\
\hline Organisation & $\begin{array}{l}\text { Carried on individually } \\
\text { or through workshops }\end{array}$ & $\begin{array}{l}\text { Workshop with inter- } \\
\text { active participation }\end{array}$ & $\begin{array}{l}\text { Individual or with } \\
\text { workshops as part of } \\
\text { the process }\end{array}$ \\
\hline Technology & SWOT-matrix & $\begin{array}{l}\text { Tools and } \\
\text { techniques that } \\
\text { support workshops }\end{array}$ & $\begin{array}{l}\text { Techniques for } \\
\text { construction of } \\
\text { scenarios }\end{array}$ \\
\hline $\begin{array}{l}\text { OR-worker } \\
\text { function }\end{array}$ & $\begin{array}{l}\text { Expert/analyst/ } \\
\text { facilitator }\end{array}$ & Facilitator & $\begin{array}{l}\text { Expert/analyst/ } \\
\text { facilitator }\end{array}$ \\
\hline
\end{tabular}

The future workshop is on the other hand far from the traditional OR in especially one concept: the objectivity. Throughout the whole workshop, focus is on giving room to subjectivity. We define objectivity here as intersubjectivity and consensus. One can say that it is the subjectivity that drives the process. Even though the workshop in some forms tries to give a total description of strategy development, it is not developed or built to deal with these issues. Decision-makers must carry on work on the visible products-the strategies. The future workshop supports a learning process for the individuals participating. This support is built into the approach's way of working. Products, therefore, can be found in all four categories. However, in the idea behind the workshop lies a special focus on the invisible products. The organisation as such is not given any special consideration. It is assumed that all individuals participate without any power relations implicating the situation. The technology used is tools and techniques that support workshops (as for example brainstorming) and there is not specific modelling or problem solving techniques. The future workshop requires a facilitator.

SODA supports also a group process however more indirectly by focusing on the individuals and gathering their opinions on the problematic situation before a real workshop is carried out. Through its way of working and its view on individuals in the organisation, SODA supports a learning process and gives products in all four categories. Again all participants are seen as equal members of the workshop, and there are only given consideration to the organisation by selecting the individuals for the interviews and for the workshop. The technology (the cognitive maps) in SODA is focused more on the individuals than on dealing with the group. The OR-worker is especially important in SODA. He is the one that analyses the maps, merges maps and 
discusses the issues. This can be carried out using a whiteboard, paper or by use of the existing software Decision Explorer (Banxia Software Limited, 1996). Indirectly (or perhaps in some cases directly) he may set the outline for the workshop. The OR-worker must be a facilitator but also an analyst and perhaps expert in using the cognitive maps.

Table 3 Overview of the evaluation of the approaches SODA, SCA and SSM

\begin{tabular}{|c|c|c|c|}
\hline $\begin{array}{l}\text { Characteristics } \\
\text { of }\end{array}$ & SODA & SCA & SSM \\
\hline Background & $\begin{array}{l}\text { Psychology/social } \\
\text { psychology }\end{array}$ & OR/decision theory & Systems Engineering \\
\hline Focus & $\begin{array}{l}\text { Support in percep- } \\
\text { tion and structuring } \\
\text { of a messy problem } \\
\text { situation }\end{array}$ & $\begin{array}{l}\text { Analytical support of } \\
\text { depending } \\
\text { areas }\end{array}$ & $\begin{array}{l}\text { Structuring of a messy } \\
\text { problem situation }\end{array}$ \\
\hline Process & $\begin{array}{l}\text { Learning process } \\
\text { where dialectic think- } \\
\text { ing comes from } \\
\text { analysing individual } \\
\text { perceptions and } \\
\text { these are gathered in } \\
\text { an aggregated model }\end{array}$ & $\begin{array}{l}\text { Learning process } \\
\text { where there is a } \\
\text { dialectic interchange } \\
\text { between different ways } \\
\text { of working }\end{array}$ & $\begin{array}{l}\text { Learning process } \\
\text { where individual world } \\
\text { views are described } \\
\text { and systematised }\end{array}$ \\
\hline Products & $\begin{array}{l}\text { Products in all cate- } \\
\text { gories. Special focus } \\
\text { on invisible products }\end{array}$ & $\begin{array}{l}\text { Products in all } \\
\text { categories }\end{array}$ & $\begin{array}{l}\text { Products in all } \\
\text { categories. Special } \\
\text { focus on invisible } \\
\text { products }\end{array}$ \\
\hline Organisation & $\begin{array}{l}\text { Individual interviews } \\
\text { and workshops }\end{array}$ & $\begin{array}{l}\text { Workshops with inter- } \\
\text { active participation }\end{array}$ & $\begin{array}{l}\text { Description between } \\
\text { client-system and root } \\
\text { definitions. Workshops } \\
\text { with interactive partici- } \\
\text { pation }\end{array}$ \\
\hline Technology & $\begin{array}{l}\text { Cognitive maps and } \\
\text { use of software. } \\
\text { Tools and tech- } \\
\text { niques for supporting } \\
\text { workshops }\end{array}$ & $\begin{array}{l}\text { Tools and techniques } \\
\text { for modelling use of } \\
\text { software. Tools and } \\
\text { techniques for } \\
\text { supporting workshops }\end{array}$ & $\begin{array}{l}\text { Modelling techniques } \\
\text { based on systems } \\
\text { thinking }\end{array}$ \\
\hline $\begin{array}{l}\text { OR-worker } \\
\text { function }\end{array}$ & $\begin{array}{l}\text { Facilitator } \\
\text { analyst }\end{array}$ & $\begin{array}{l}\text { Facilitator and expert } \\
\text { in methodology }\end{array}$ & $\begin{array}{l}\text { Facilitator and expert } \\
\text { on the approach acting } \\
\text { in different roles }\end{array}$ \\
\hline
\end{tabular}

SCA is clearly a methodology that in explicit form takes up with the traditional methods in terms of assuming full information and certainty. SCA is fundamentally developed to accept uncertainties associated with problematic situations and decisions. SCA has a very analytical way of working with the problematic situation and developing strategies. Anyhow, the SCA supports a learning process by changing between different ways of working and the cyclic view on the process. Products can be obtained in all four categories. However, the focus (in the end) is more on the visible products of substance. It is assumed that SCA is organised through a workshop with interactive participation of decisionmakers. As such people are considered to be equally placed in the organisational hierarchy. SCA is dependent upon a ENGEVISTA, v. 7, n. 1, p. 4-20, abril 2005 facilitator who also must be expert in the approach and the different technologies that make up the approach. Also SCA can be supported by existing software named STRAD (Stradspan Limited, 1994).

SSM is a classical example on a soft OR approach. The methodology has a cyclic, iterative approach to strategy development. Focus lies on subjective values and perceptions, the problem is never solved but structured, and explicit cause-effect relations are modelled (using conceptual models). Even though SSM does not address uncertainties, there lies an indirect recognition of the presence of uncertainties. Through its cyclic way of working and the acknowledgement that problems are never solved but must be monitored and dealt with almost continuously, it deals with future uncertainties in the way that decisions 
are never definitive but can and must be changed all the time. The functionality of SSM is however dependent upon the fundamental assumptions that reflect the organisation in focus. SSM is based on principles of a learning process, systems thinking, and focus is on the invisible products. However, products in all categories are found. The organisation as such is dealt with through the individual world-views and the descriptions of these. The way of working with the real world and then seeing systematically on things may be rather difficult for some individuals. It is, therefore, very dependent upon the OR-worker to facilitate this process and be an expert in how the different technologies are dealt with.

\section{REFLEXIONS}

The characterisation presented in the last section based on dimensions of the diamond provides a multidimensional insight into each of the discussed soft approaches. This insight is valuable dealing with real-life problematic situations since in practice several approaches often will be combined within

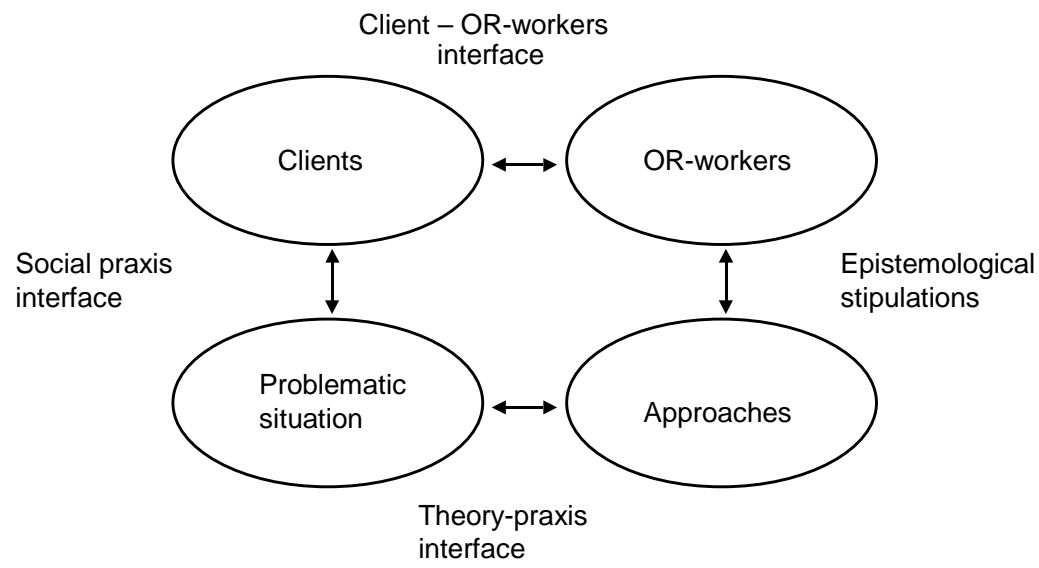

Figure 4 The social process framework

The clients are the group, individual or organisation with a problematic situation or decision problem. They are the decision makers and/or problem owners with individual subjective perceptions on the problematic situation. They can describe the problem (from their point of view) and give judgements about possible actions. It is not always easy to identify the clients of the organisation since they can be placed at any level or in any group of the organisation and not necessarily are placed ENGEVISTA, v. 7, n. 1, p. 4-20, abril 2005 a problem-solving framework (see for instance Ormerod, 1999).

The limitation of our inquiry resides in the fact that we are only focusing on the anatomy of the soft approaches. However, the context (the real-life situation) in which the approaches will be applied is as well an important factor that will influence on the selection of approaches and the final outcome of a given problem solving process.

The social reality for applying soft approaches is based on the process in which it is used-here referred to as the social process. In its more elementary form, the social process is constituted by four elements: the clients, the OR-worker, the approach applied, and the problematic situation in focus. The dynamic interplay of the four elements interact in different ways, and it is these interactions that define the social process, how soft approaches can be applied, and the outcome of this application. Figure 4 illustrates the social framework and the interactions between the four elements.

in the well-defined group. The ORworkers are consultants that have specialised tools to deal with the problematic situation. They may be a part of the same organisation as the clients but more often they are not. They can play different roles: facilitators, experts, advisors, analysts, etc. The problematic situation is any mess that needs to be solved or dealt with through a problem solving process. Usually, the problematic situation is characterised through a focus 
on systems and problematic decision areas. The problematic situation can, however, also involve actions in the sense that interrelations between members of the organisation can constitute the problematic situation. An approach is applied either to organise, to structure or to model the problematic situation.

Between the elements and the way they interact, contradictions can be identified determining and controlling the social process and the outcome of the process. Contradictions are here broadly defined as controversies, unsuitability, conflicts, differences of opinions, etc., that give contrast in perceptions and descriptions of the problematic situation. They are implicitly or explicitly always present in a problem solving process.

Contradictions may be originated by objective reasons existing for the interaction. Such example may be a buyer - seller relationship where both the client and the OR-worker know about he situation and its premises but have differences in spite of this. Contradictions can also be originated due to subjective reasons and placements in the organisation. An example can be different problem views of a production chief and a sales chief in a company focusing on expanding the market. Contradictions usually involve individuals but the term can also be used in the case that an approach is not appropriate for a problematic situation.

Contradictions are present in decision making at all times but are to a certain extent controlled by traditional or strict ways of dealing with problematic situations. In this situation, clients and ORworkers have well-established roles, have recognised approaches to use and ways of applying them. In complex (messy) problem situations, the roles of the actors must be established based on the premises of their interaction. The problem situation must be described and recognised as a new type of problem.

Contradictions cannot always be solved, resolved, or addressed completely (as it would be attempted by establishing consensus). They can be controlled or dealt with to a certain extent. However, they may retain in a latent state and their negative potential might show again later in time and grow in importance as conditions change.

Figure 3 outlines various sources for contradictions-the linkages between the four elements. The interaction between the OR-worker and the approaches is ruled by contradictions linked to epistemological stipulations. The OR-worker normally will choose and use approaches of their epistemological traditions and experiences. The analysts can only perceive and work with the problem situation and the approaches in terms, they know of. Every scientific field and school of thought has their own perceptions, traditions, ways of describing problems and dealing with these. Assumptions, ways of limiting the problem description and applying the approach may all be in conflict with the real world (perhaps the perception of the clients). Contradictions (conflicts) arise because of different perceptions, limitations in the way analysts epistemologically can see the problem, limitations in the approach itself, conflicting assumptions and interests, lack of directing the problem as it is without using approaches that always are used, etc. Also OR-workers may view the problem from their own point of view and have political interests associated with the problem solving. In that way, they may add to the contradictions of the epistemological interactions. The ORworkers are in many situations also responsible fore presenting and translating the results of the methodological application for the clients. In this presentation epistemological limitations also lie in how they can make reflexions and present the results from objective and neutral perspectives. Hard, soft and critical approaches represent different epistemological assumptions about scientific work.

The contradictions between the problematic situation and approaches are associated with the theory-praxis interactions. These contradictions have to do with successful problem solving and 
implementation of approaches. There are two sides to the contradictions of the theory-praxis interactions; how well or appropriate the approach used, captures the problematic situation, and how well clients understand and identify themselves with the approach used. This interaction is often ruled by traditional ways of looking upon problematic situations using a strategic and political view on them. In this way of looking at the problem, there may also be limitations to the detail or broadness of the problem. Having a perception of a problematic situation, clients often have an expectation to the results of the analysis. This means that the clients have an idea of how solutions should be investigated and represented. Often this again is based on traditions and experience. Using an approach, which perhaps directs the problem situation better but not has been introduced to the clients before, there is a risk that the clients have reluctance towards using the approach and its results. This also means that the approach has a central role in the description and translation of the problem situation and the way it is solved, perceived, understood and accepted by the clients.

The social-praxis interface has to do with the contradictions that are present between the clients and the problematic situation. In praxis, the clients own the problem and must act upon it. The clients are also the ones who in reality determine or set the frames for how the problem situation shall be looked upon and solved by the OR-worker. The social and political function of the clients as well as public and inter-organisational opinion may be determining for how the clients respond to the problematic situation.

When two groups interact to support each other, there is always a risk of conflicts at the socio-psychological level that must be managed some way. These risks will differ according to the nature of the relationship and contradictions may arise as a consequence of the so-called client - OR-worker interaction. The two groups might belong to different organisations with different traditions, culture, nationality, and might also reflect other contradictions in society. Even if both clients and OR-worker recognise the same problem, they do not necessarily perceive the problem in the same way. Also the problematic situation can be interlinked with other problematic situations that can complicate the relationship between the clients and the OR-worker. In some situations, the relationship is based on political aspects that may disregard the technical considerations and constraints and runs the risk of being only an example of policy planning. In other situations, OR-workers may isolate themselves from the clients and potential socio-political contradictions. In this situation, the study will not raise interest by clients, who see it as an academic exercise.

Finally, it shall be mentioned that other contradictions often are present. These have to do with internal conflicts among the individuals in the groups of actorsbetween the clients and OR-workers. Important sources of conflict are the power relations related to who coordinates and finances the studies, the view on the problem situation, and inter-personal, human relations.

Obviously, any OR intervention to tackle problematic situations has to reflect on the above mentioned interactions and contradictions before selecting and using soft approaches, while carrying out the intervention and the end while evaluating the whole process. Moreover, failures in tackling problematic situations might give fruitful insight into the abilities (strengths/weaknesses) of an organisation to cope with messes; this is often called learning from failure (Fortune and Peters, 1995).

\section{CONCLUSIONS}

Our inquiry into the nature and characteristics of soft approaches has taken us through what we call the anatomy of soft approaches. The study shows that characterising soft approaches not only can be based on quantitative or qualitative modelling aspects and systems thinking. A multi-dimensional framework is needed to outline the many different facets and 
possibilities. Here, we have proposed one framework that in principle also can be used to select 'the right' approach for a particular problematic situation.

However, the limitations of discussing only the anatomy of soft approaches-and the characterisation framework-are clear. When it comes to reality, it is more often the dimensions of the social process that determine whether a soft approach is proper for a specific situation or not. No matter which approach is chosen, it will be perceived in different ways leaving parts of the problem situation unsolved or outside the scope of the methodology.

Assumptions are needed at some level to deal with problem situations and problem solving processes. However, methodological applications, and rational, conscious actions are not enough, experience, intuition, creativity, and subjectivity are other ingredients needed in the process. Practice has shown that it is a good idea at the beginning of a problem situation to start with the application of one or several of these approaches. After some applications, a learning process will develop into a situation where the participating group of individuals does not need any longer a facilitator (OR-worker) and has designed its own approach on the basis of their experiences.

Real-life applications of soft OR approaches can be found in Vidal (2004).

\section{References}

Ackoff, R.L. (1979) Resurrecting the Future of Operational Research, Journal of the Operational Research Society 30 (3) 189-199.

Banxia Software Limited (1996) Decision Explorer. When Decision Matter. Reference Manual, Department of Management Science, University of Strathclyde, Glasgow.

Checkland, P. (1981) Systems Thinking, Systems Practice, John Wiley \& Sons, Chichester.

Daellenback, H.G. (1994) Systems and Decision Making - A Management Science Approach, John Wiley \& Sons, Chichester.
Dyson, R.G., O’Brien, F.A., 1998. Strategic Development Methods and Models, John Wiley \& Sons, Chichester.

Eden, C. (1988) Cognitive Mapping, European Journal of Operational Research, 36 (1) 1-13.

Flood, R.L., Jackson, M.C. (1991) Creative Problem Solving: Total Systems Intervention, John Wiley \& Sons, Chichester.

Fortune, J., Peters, G. (1995) Learning from Failure: The Systems Approach, John Wiley \& Sons, Chichester.

Friend, J., Hickling, A. (1997) Planning under Pressure. The Strategic Choice Approach, Butterworth-Heinemann, Oxford.

Godet, M. (1987) Scenarios and Strategic Management, Butterworths, London.

Jungk, R., Müllert, N. (1987) Future Workshops. How to Create Desirable Futures, Institute for Social Inventions, London

Kahn, H., Wiener, A.J. (1967) The Year 2000. A Framework for Speculation on the Next Thirty-Three Years, The Macmillan Company. New York.

Keys, P. (1991) Operational Research and Systems: The Systemic Nature of Operational Research, Plenum Press, London.

Mason, R.O., Mitroff, I.I. (1981) Challenging Strategic Planning Assumptions, John Wiley \& Sons, New York.

Ormerod, R. (1999) Putting Soft OR Methods to Work: the Case of Business Improvement Project at Powergen, European Journal of Operational Research, 18 (1) 1-29.

Pidd, M. (1996) Tools for ThinkingModelling in Management Science, John Wiley \& Sons, Chichester.

Richie, C., Taket, A., Bryant, J. (1994) Community works: 26 case studies showing community Operational Research in action, Community Operational Research Unit Publications: Number 1, PAVIC publications, Sheffield Hallam University, Birmingham.

Rosenhead, J. (ed.) (1989) Rational Analysis for a Problematic World. Problem Structuring Methods for 
Complexity, Uncertainty and Conflict, John Wiley \& Sons, Chichester.

Rosenhead, J. (1996) What's the Problem? An Introduction to Problem Structuring Methods, Interfaces, 26 (6) 117-131.

Stradspan Limited, (1996). STRAD to strategic advisors. Users manual, version 2 for Windows, Sheffield Science Park, Sheffield.

Sørensen, L., Vidal, R.V.V. (1999) Strategy development and planning as learning processes-six soft approaches, In Danish, Copenhagen Business School Press, Copenhagen.

Vidal, R.V.V. (1995) How to teach/learn OR? Investigacão Operacional, 15, 97-110. Vidal, R.V.V., 1996. Scenario. Methods and Applications, CTI Working Paper no. 20, Center for Tele-Information, Technical University of Denmark, Lyngby, (Downloadable form website http://www.cti.dtu.dk/ publications/workingpaper.php.

Vidal, R.V.V. (ed.) (2004) Applications of Soft OR Methods, Special Issue, European Journal of Operational Research, 152 (3) 529-722.

Weihrich, H. (1982) The TOWS Matrix: A Tool for Situational Analysis, Long Range Planning, 15 (2) 54-66. 